\title{
Smoking cessation guidelines for health professionals: an update
}

\author{
Robert West, Ann McNeill, Martin Raw
}

\begin{abstract}
This paper updates the evidence base and key recommendations of the Health Education Authority (HEA) smoking cessation guidelines for health professionals published in Thorax in 1998. The strategy for updating the evidence base makes use of updated Cochrane reviews supplemented by individual studies where appropriate. This update contains additional detail concerning the effectiveness of interventions as well as comments on issues relating to implementation. The recommendations include clarification of some important issues addressed only in general terms in the original guidelines. The conclusion that smoking cessation interventions delivered through the $\mathrm{Na}$ tional Health Service are an extremely cost effective way of preserving life and reducing ill health remains unchanged.
\end{abstract} The strategy recommended by the guidelines involves: (1) GPs opportunistically advising smokers to stop during routine consultations, giving advice on and/or prescribing effective medications to help them and referring them to specialist cessation services; (2) specialist smokers' services providing behavioural support (in groups or individually) for smokers who want help with stopping and using effective medications wherever possible; (3) specialist cessation counsellors providing behavioural support for hospital patients and pregnant smokers who want help with stopping; (4) all health professionals involved in smoking cessation encouraging and assisting smokers in use of nicotine replacement therapies (NRT) or bupropion where appropriate. The key points of clarification of the previous guidelines include: (1) primary health care teams and hospitals should create and maintain readily accessible records on the current smoking status of patients; (2) GPs should aim to advise smokers to stop, and record having done so, at least once a year; (3) inpatient, outpatient, and pregnant smokers should be advised to stop as early as possible and the advice recorded in the notes in a readily accessible form; (4) there is currently little scientific basis for matching individual smokers to particular forms of NRT; (5) NHS specialist smokers' clinics should be the first point of referral for smokers wanting help beyond what can be provided through brief advice from the GP; (6) help from trained health care professionals specialising in smoking cessation such as practice nurses should be available for smokers who do not have access to specialist clinics; (7) the provision of specialist NHS smokers' clinics should be commensurate with demand; this is currently one or two full time clinics or their equivalent per average sized health authority, but demand may rise as publicity surrounding the services increases. (Thorax 2000;55:987-999)

Keywords: smoking cessation; guidelines; nicotine replacement therapy; bupropion

Background

The Health Education Authority (HEA) national smoking cessation guidelines published in Thorax in December $1998^{1}$ set out recommendations for ways in which the National Health Service (NHS) could treat tobacco dependence and reduce the burden of death and ill health which tobacco causes.

The recommendations were based on the research findings current at the time. It was always intended that the guidelines would be updated periodically as new evidence emerged and experience was gained with implementation. This paper updates the evidence base for the guidelines and revises the guidelines in the light of this experience. It also amends the presentation of the evidence and the recommendations to take account of feedback received on the original guidelines. Some issues have not changed - for example, the role of local and national initiatives such as No Smoking Day (NSD) in raising awareness of the importance of smoking cessation and the availability of services-and are not discussed further in this update.

One important change has been the publication of a government White Paper on tobacco control ${ }^{2}$ which has provided a budget to develop new smoking cessation treatment services, initially for three years. This has meant national implementation of new services and this update takes account, where possible, of issues emerging from this new initiative. 


\section{Recommendations}

See text for explanation of strength of evidence ratings $\mathrm{A}, \mathrm{B}$, and $\mathrm{C}$.

\section{Primary health care teams}

1 Primary health care teams should ensure that their records concerning which of their patients smoke are kept up to date. [A]

2 GPs should advise current smokers to stop during routine consultations at least once a year, offer a prescription for NRT or bupropion, offer further support by way of a referral to a specialist clinic or other specialist service, record the response to that advice, and arrange follow up where appropriate. [A]

3 Practice nurses should be prepared to encourage known smokers to stop and offer assistance where possible. [C]

4 GPs and practice nurses should receive sufficient practical and theoretical training to enable them to deliver opportunistic advice to encourage a cessation attempt, and to offer accurate advice on NRT or bupropion. [A]

5 Other primary health care team professionals should be encouraged to ask about smoking and advise smokers to stop. [C]

\section{Hospitals and community trusts}

6 Hospitals and midwifery services should implement efficient systems for recording the smoking status of outpatients and inpatients and keeping these records up to date. [A]

7 Hospitals should be smoke-free and all patients should be advised of this at the earliest opportunity-for example, for elective admissions it should be stated in correspondence before the patient arrives. [C]

8 Where practicable, current smokers attending hospital should receive opportunistic advice from a clinician similar to that described above for GPs and the advice should be recorded in the notes. [A]

9 Hospital inpatients and outpatient smokers should be offered specialist support and hospital outpatients should be offered NRT or bupropion on NHS prescription. [A]

10 Pregnant smokers should receive clear, accurate, and specific information on the risks of smoking to the fetus and themselves and be advised to stop smoking. [A]

11 Pregnant smokers should be offered specialist support with stopping smoking. [A]

12 Clinicians, midwives, and other staff who may be involved in discussing smoking with patients or clients should receive adequate training to enable them to do this effectively. [C]

\section{Specialist smoking cessation clinics}

13 Where possible smokers should have access to a specialist smokers' clinic. [A]

14 Specialist clinics and other support services should be staffed by individuals specially trained and employed for the purpose rather than attempting to fit the job in with other duties. [A]

15 The extent of provision of specialist smokers' clinics should be commensurate with demand. [C]

16 Clinics should offer both individual and group treatment. [A]

17 Specialist services should incorporate advice to use NRT or bupropion into the regimen. [A]

18 The withdrawal orientated treatment model offers a practicable and proven system for most specialist services. [C]

\section{Health care purchasers}

19 Purchasing smoking cessation interventions represents an extremely cost effective way of reducing ill health and prolonging life. $[\mathbf{A}]$

20 The precise blend of intervention elements (opportunistic advice, specialist support from trained staff, specialist clinics, free NRT, etc) will depend on the local circumstances, but it should place greatest emphasis on elements that have the strongest evidence base. [A]

21 Consideration should be given to establishing a core syllabus and national accreditation for training for opportunistic interventions and for those delivering the specialist services to ensure a minimum standard. [C]

22 Training for those not paid to do smoking cessation as a main part of their work should be purchased to enable cessation interventions to be implemented effectively; this should not detract from funding for a core specialist service. [A]

\section{Pharmacotherapies (NRT and bupropion)}

23 Smokers of 10 or more cigarettes per day should normally be encouraged to use NRT or bupropion. [A]

24 There is currently no scientific basis for recommending one form of NRT over others. [B]

25 There is no scientific basis for disallowing different forms of NRT to be combined and there may be some benefit to combinations. [B]

26 NRT can be recommended for use in patients with cardiovascular disease but only with the agreement of the patient's physician if the disease is acute or poorly controlled. [B]

27 Use of NRT by pregnant smokers may benefit the mother and fetus if it leads to cessation of smoking. [C]

28 NRT may aid smoking cessation in adolescent smokers but there is insufficient evidence yet to make a recommendation. [C]

29 No recommendation can currently be made concerning the circumstances in which bupropion should be preferred over NRT or vice versa other than those for which one of the drugs is contraindicated. [B]

30 No recommendation can be made regarding the use of NRT and bupropion in combination. [B]

31 Both NRT and bupropion should be available on NHS prescription. [A]

32 Both bupropion and NRT should be prescribed for relatively short durations at a time and the prescriptions only repeated if the quit attempt is continuing. [A] 
When the original guidelines were published, the high cost effectiveness of smoking cessation interventions was demonstrated in an accompanying article. ${ }^{3}$ These data are still relevant ${ }^{4}$ and are not updated here.

The updated guidelines have benefited from the following important documents published in 2000: The National Service Framework for Coronary Heart Disease published by the Department of Health ${ }^{5}$; Treating Tobacco Use and Dependence, an updated clinical practice guideline on the treatment of tobacco dependence published by the US Department of Health and Human Services (USDHHS) ${ }^{6}$; the database on smoking cessation interventions and their effectiveness of the Society for Research on Nicotine and Tobacco $\left(\right.$ SRNT) ${ }^{7}$; the submission by ASH to the NHS Modernisation Review on smoking cessation in primary care $^{4}$; the report by ASH/Health Development Agency on provision of smoking cessation services in the $\mathrm{NHS}^{8}$; The Royal College of Physician's report on nicotine addiction in Britain $^{9}$; and the NHS publication entitled $A$ Plan for Investment, a Plan for Reform. ${ }^{10}$

As with the first version of the guidelines, this update has been prepared in consultation with an expert panel of researchers and practitioners (see appendix A). The guidelines have also been endorsed by a number of organisations (see appendix B).

\section{Evidence base}

PRINCIPLES ADOPTED IN UPDATING THE EVIDENCE BASE

The strategy for the original guidelines was to rely on meta-analyses which combined the results of several (and, in some cases, a large number of) studies to arrive at a single estimate of efficacy of a specific type of interventionfor example, brief GP advice. Two key sets of meta-analyses were used: those from the Cochrane Collaboration, and those included in the smoking cessation guideline published by the Agency for Health Care Policy Research (AHCPR; now called the Agency for Healthcare Research Quality (AHRQ)). ${ }^{11}$ The advantage of this approach is that it systematically combines evidence from different trials. The disadvantages are that it does not allow for new studies that have not yet made their way into the reviews; it can mask important distinctions between interventions which are all classed as the same; it does not permit statements about interventions that have not been subject to systematic reviews; and the studies come largely from populations (primarily the US) that may be different from the population of interest.

For the update it was decided to focus, as before, on systematic reviews, but to supplement these by additional findings where relevant. The additional findings were sought by monitoring of online research databases involving all research that mentioned "smoking", "nicotine", or "tobacco" in the abstract or title. It was also decided to provide more detail of the findings relating to the effectiveness of particular interventions. This was because experience with implementation of the previous guidelines indicated that there was a need for guidance on issues that had not previously been covered - for example, the effectiveness of counselling by health care professionals given opportunistically during consultations and comparisons between different forms of nicotine replacement.

We then reformulated the categories of intervention so that, instead of distinguishing between very brief interventions, brief interventions, and intensive interventions, the major categories arrived at were "Brief opportunistic advice to stop from a health care professional" and "Behavioural support to aid quit attempts". The reason is that this more closely reflects the main types of situation that health professionals encounter. In the former case, the main aim is proactively to trigger a quit attempt while, in the latter case, the emphasis is on responding to smokers' requests for help with a quit attempt (equivalent to the government's intermediate and specialist support categories). Other interventions can also trigger quit attempts such as mass media campaigns and NSD.

In addition, greater consideration was given to evidence on implementation, recognising that efficacy demonstrated in randomised controlled trials may not translate into effectiveness in real health care settings (we use the term "efficacy" to denote positive outcomes from clinical trials and "effectiveness" to denote positive effects in clinical practice). It also recognises that there are major barriers to implementation that need to be considered when designing interventions that can be adopted across the NHS.

In considering which systematic reviews to include, it was decided, for the following reasons, to focus on those undertaken by the Cochrane Collaboration: (1) these reviews concentrate on studies in which direct comparisons are made between intervention and control groups rather than attempting to compare different studies. Comparisons between different groups in different studies run a risk of bias resulting from differences in the samples studied; (2) the Cochrane reviews use abstinence for at least six months as the primary outcome measure. Other reviews which use abstinence at shorter follow up points require additional assumptions to be made about how far these will translate into long term cessation; (3) the Cochrane reviews are updated regularly; and (4) they provide details of methods and results of studies included so it is possible to identify subgroups of studies that can be used for particular comparisons.

FINDINGS

For each type of intervention the evidence on its efficacy is presented, followed by evidence relating to implementation which may affect recommendations to health professionals. Efficacy is quantified in terms of the proportions of all smokers receiving the intervention who stop smoking over and above those (in the control group) who would have stopped anyway-that is, we give the incremental cessation rate. The main findings are given in table 1 . 
Table 1 Incremental effects of smoking cessation interventions on abstinence for six months or longer

\begin{tabular}{|c|c|c|c|}
\hline Intervention & Target population & Effect size $e^{a}$ & $\begin{array}{l}95 \% \text { confidence }^{-} \\
\text {interval }^{b}\end{array}$ \\
\hline $\begin{array}{l}\text { Brief opportunistic advice from } \\
\text { a physician to stop }\end{array}$ & $\begin{array}{l}\text { Smokers attending GP } \\
\text { surgeries or outpatient } \\
\text { clinics }\end{array}$ & $2 \%$ & $1 \%$ to $3 \%$ \\
\hline $\begin{array}{l}\text { Face to face intensive } \\
\text { behavioural support from a } \\
\text { specialist }^{\mathrm{c}}\end{array}$ & $\begin{array}{l}\text { Moderate to heavy smokers } \\
\text { seeking help with stopping }\end{array}$ & $7 \%$ & $3 \%$ to $10 \%$ \\
\hline $\begin{array}{l}\text { Face to face intensive } \\
\text { behavioural support from a } \\
\text { specialist }\end{array}$ & Pregnant smokers & $7 \%$ & $5 \%$ to $9 \%$ \\
\hline $\begin{array}{l}\text { Face to face intensive } \\
\text { behavioural support from a }_{\text {specialist }^{\mathrm{d}}}\end{array}$ & $\begin{array}{l}\text { Smokers admitted to } \\
\text { hospital }\end{array}$ & $4 \%$ & $0 \%$ to $8 \%$ \\
\hline $\begin{array}{l}\text { Proactive telephone } \\
\text { counselling }^{\mathrm{e}}\end{array}$ & $\begin{array}{l}\text { Smokers wanting help with } \\
\text { stopping but not receiving } \\
\text { face to face support }\end{array}$ & $2 \%$ & $1 \%$ to $4 \%$ \\
\hline Written self-help materials & $\begin{array}{l}\text { Smokers seeking help and } \\
\text { not receiving other support }\end{array}$ & $1 \%$ & $0 \%$ to $2 \%$ \\
\hline Nicotine gum & $\begin{array}{l}\text { Moderate to heavy smokers } \\
\text { receiving limited behavioural } \\
\text { support }^{\mathrm{f}}\end{array}$ & $5 \%$ & $4 \%$ to $6 \%$ \\
\hline Nicotine gum & $\begin{array}{l}\text { Moderate to heavy smokers } \\
\text { receiving intensive } \\
\text { behavioural support }\end{array}$ & $8 \%$ & $6 \%$ to $10 \%$ \\
\hline Nicotine transdermal patch & $\begin{array}{l}\text { Moderate to heavy smokers } \\
\text { receiving limited behavioural } \\
\text { support }\end{array}$ & $5 \%$ & $4 \%-7 \%$ \\
\hline Nicotine transdermal patch & $\begin{array}{l}\text { Moderate to heavy smokers } \\
\text { receiving intensive } \\
\text { behavioural support }\end{array}$ & $6 \%$ & $5 \%$ to $8 \%$ \\
\hline Nicotine nasal spray & $\begin{array}{l}\text { Moderate to heavy smokers } \\
\text { receiving intensive } \\
\text { behavioural support }\end{array}$ & $12 \%$ & $7 \%$ to $17 \%$ \\
\hline Nicotine inhalator & $\begin{array}{l}\text { Moderate to heavy smokers } \\
\text { receiving intensive } \\
\text { behavioural support }\end{array}$ & $8 \%$ & $4 \%$ to $12 \%$ \\
\hline Nicotine sublingual tablet & $\begin{array}{l}\text { Moderate to heavy smokers } \\
\text { receiving intensive } \\
\text { behavioural support }\end{array}$ & $8 \%$ & $1 \%$ to $14 \%$ \\
\hline $\begin{array}{l}\text { Bupropion ( } 300 \mathrm{mg} / \text { day } \\
\text { sustained release) }\end{array}$ & $\begin{array}{l}\text { Moderate to heavy smokers } \\
\text { receiving intensive } \\
\text { behavioural support }\end{array}$ & $9 \%$ & $5 \%$ to $14 \%$ \\
\hline $\begin{array}{l}\text { Intensive behavioural support } \\
\text { plus NRT or bupropion }\end{array}$ & $\begin{array}{l}\text { Moderate to heavy smokers } \\
\text { seeking help from a } \\
\text { smokers' clinic }\end{array}$ & $13-19 \%$ & - \\
\hline
\end{tabular}

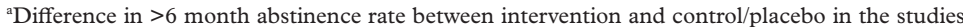
reported; data from Cochrane meta-analyses unless otherwise stated.

${ }^{\mathrm{b}}$ The range within which one can be $95 \%$ confident that the true underlying value lies.

${ }^{c}$ Efficacy figures based on subset of studies from general population with biochemical verification. ${ }^{\mathrm{d} N o}$ Cochrane review available, data from USDHHS meta-analysis. ${ }^{6}$

${ }^{\text {} N o}$ Cochrane review available, data from USDHHS meta-analysis. ${ }^{6}$

"The term "limited behavioural support" refers to brief sessions required primarily for collecting data. Following the Cochrane definition, "intensive" behavioural support was defined as an initial session of more than 30 minutes, or an initial session of less than 30 minutes plus more than two subsequent visits.

${ }^{g}$ Expected effect combining effect of medication with effect of behavioural support.

\section{RECOMMENDATIONS}

As in the original guidelines, we have classified the recommendations according to the strength of evidence as follows: A: Many well designed randomised controlled trials directly relevant to the recommendation, yielding a consistent pattern of findings. B: Some evidence from randomised controlled trials, but not optimal. More interpretation of the evidence was needed. For example, there were not many randomised controlled trials, their results were not consistent, they were not directly relevant to the recommendation. They may not have been directly relevant because, for example, the study population was different. C: No randomised controlled trials but the issue is important enough to merit a recommendation which is based on published evidence and expert opinion of the authors and reviewers.

In some cases the recommendation is not a matter of empirical evidence but is a prerequisite for another recommendation that is supported by the evidence. In this case, the strength of evidence is also derived from the related recommendation.

NICOTINE REPLACEMENT THERAPY (NRT) AND BUPROPION ON THE NHS

At the time of writing the government had announced that bupropion and NRT (the latter following consultation only) would be available on NHS reimbursable prescriptions. The National Institute of Clinical Excellence was also being asked to advise GPs on the most appropriate and cost effective prescribing regimes for NRT and bupropion. In this document we assume that both NRT and bupropion will be available on the NHS and have made comments in the text where appropriate to support this assumption.

\section{Brief opportunistic advice to stop from a} health care professional

This consists of brief advice from health professionals (such as dentists and the dental team, GPs, health visitors, midwives, pharmacists, physiotherapists, practice nurses) delivered opportunistically during routine consultations to smokers whether or not they are seeking help with stopping. Brief opportunistic advice typically involves asking patients about their current smoking, advising them to stop, offering assistance by way of a referral to a specialist service, advice or a prescription for NRT or bupropion (see below), and arranging follow up where appropriate.

\section{EFFICACY}

1 Brief advice (up to 5 minutes) from a GP given to all smokers to encourage them to make an attempt to quit is effective in promoting smoking cessation-the four As (ask, advise, assist, arrange; table 1). This advice leads to $1-3$ out of 100 smokers receiving it to stop smoking for at least six months. ${ }^{12}$ This is in addition to the number who would have stopped smoking anyway. It is estimated that approximately $40 \%$ of smokers make some form of attempt to quit in response to advice from a GP..$^{13}$

2 This advice appears to have its effect primarily by triggering a quit attempt, rather than by increasing the chances of success of quit attempts. ${ }^{13}$

3 There is insufficient evidence yet to say whether similar advice from other health care professionals is effective. A wide range of health professionals such as practice nurses already undertake opportunistic advice on smoking cessation to some degree. There is interest among other health professionals in becoming more involved in such opportunistic advice but, as yet, there is insufficient evidence from randomised controlled trials to know whether this is effective. ${ }^{6}$ For example, research has failed to find any effect of advice given to patients attending accident and emergency departments. ${ }^{15}$ However, it remains possible that factors such as access to smokers, level of 
training, experience, and commitment are more important than professional discipline.

4 Without provision of pharmacotherapy as well, this advice primarily affects light smokers. In general it is those who smoke less than 10 per day who stop in response to brief GP advice unless some additional assistance or medication is used. ${ }^{12}$

\section{IMPLEMENTATION ISSUES}

1 Correlational evidence suggests that repeating the advice with a given smoker has a reduced effect. One study has found that smokers who had previously been advised to stop by their family doctor were less likely to stop in response to subsequent advice. ${ }^{16}$ It is also relevant that a one year follow up of smokers found that attempting to stop within a year of a previous attempt to quit was associated with a reduced likelihood of success. ${ }^{17}$

2 GPs generally do not accept that they should give opportunistic advice at every opportunity and only a minority do this. ${ }^{18}$ Lack of time and difficulties in raising the issue uninvited appear to be major barriers. Recent research has shown that many GPs are concerned that uninvited advice to stop smoking may damage their relationship with the patient. ${ }^{19}$ However, there is no evidence that it does so.

3 GPs are more willing to give advice to stop to smokers with smoking related diseases. ${ }^{20}$ This is despite evidence that smokers with smoking related diseases do not respond better to such advice than others. ${ }^{16}$

4 Smokers may be more receptive to advice to stop when it is linked with an existing medical condition (not necessarily smoking related). There is some evidence that smokers are happier to receive advice to stop when GPs link the advice to their reason for visiting the surgery. ${ }^{21} 22$

Face to face behavioural support to aid quit attempts

This category includes a range of methods of support from focused counselling and advice, through coping skills training to group support. In fact, most programmes tested have been eclectic, involving many different components. This support is provided to smokers who are planning to make an attempt to quit and would like help with doing so.

\section{EFFICACY}

1 Behavioural support and advice from a clinic run by smoking cessation specialists is effective in aiding smoking cessation. In smokers seeking help with stopping, a programme of support involving multiple contacts for a period of four weeks or more given by specialists employed and trained for the purpose (irrespective of professional discipline) enables, on average, about one in 20 attempts to quit to succeed for six months or more that would not otherwise have done so. ${ }^{23}$ One very large study in the USA found that, with intensive protracted behavioural support, together with aggressive use of NRT, high success rates can be achieved with about one in four smokers thus treated stopping for at least a year who would not otherwise have done so. ${ }^{24}$

2 Behavioural support provided by nurses specifically employed to provide cessation advice is effective, whereas behavioural support given as part of their more general duties has not yet been shown to be effective in aiding smoking cessation. Although studies with nurses delivering counselling show a positive effect, ${ }^{25}$ no effect has been observed in studies where practice nurses have not been employed specifically to provide cessation advice. ${ }^{25} 26$

3 A structured package of behavioural support and NRT provided by pharmacists can be effective in aiding smoking cessation. Two recent randomised trials in the UK have addressed the issue of pharmacist support for smoking cessation. The first of these found a small effect that did not reach statistical significance ${ }^{27}$ while the second showed a clear and statistically significant effect on continuous abstinence for one year. ${ }^{28}$ Combined data from these two trials reveal a positive effect compared with unstructured usual care.

4 It is not yet known whether behavioural support provided by other health professionals as part of their general duties is effective. At present there are insufficient data on how far other health professionals running smoking cessation programmes in addition to their other duties can be effective.

5 It is not yet known whether providing behavioural support to smokers in groups is more or less effective than providing it individually. Although some studies have been carried out in this area, they have not been adequate to test for a difference in the two approaches. ${ }^{29}$

6 There is correlational evidence that the more time is spent with smokers the greater the effect in aiding cessation. Direct comparisons between more intensive and less intensive interventions have not been adequate to enable conclusions to be drawn but comparisons across studies suggest that more intensive interventions in terms of frequency of contact and/or duration of contact achieve higher success rates. ${ }^{6}$

7 It is not yet known whether behavioural support for adolescent smokers wanting to stop is effective. This is an area where there is ongoing research although there is as yet no clear evidence. ${ }^{30}$

8 In pregnant smokers wanting to stop, counselling from a smoking cessation specialist together with written support materials is effective in aiding cessation. Studies show that specialist support (support from someone trained and employed for the purpose) enables about one in 15 to stop smoking for the remainder of the pregnancy who would not otherwise have done so. ${ }^{31}{ }^{32}$ This generally involves one-to-one counsel- 
ling in sessions set up for the convenience of the smoker. Only a small minority of pregnant smokers are willing to attend smoking cessation groups. ${ }^{33}$

9 Behavioural support (up to 30 minutes) provided by midwives as part of their normal duties has not been shown to be effective in aiding cessation in pregnant smokers. Two large randomised trials (one in the UK and one in Denmark) which examined counselling by midwives as part of routine consultations found no effect on cessation. $^{3435}$

IMPLEMENTATION ISSUES

1 Little is known about the active ingredients of behavioural support so it is difficult to provide evidence based recommendations regarding the content of behavioural support programmes. The USDHHS guideline proposes that teaching problem solving skills and social support are useful. ${ }^{6}$ There is preliminary evidence that pairing smokers together to make the quit attempt can improve success rates ${ }^{36}$ and that, with women smokers at least, a physical activity programme can improve success rates. ${ }^{37}$

2 At present only a very small minority of smokers attend face to face sessions, whether these be specialist clinics or advice sessions run by primary care staff. ${ }^{38}$ Experience from full time clinics thus far suggests that one full time specialist clinic or its equivalent is currently adequate to meet the needs of the average sized health authority (500 000 head of population) and should be able to sustain a throughput of 300-800 clients per year. Clinics serving the needs of individual GP practices have in the past been found to be unsustainable. ${ }^{39}$ However, the numbers seeking treatment from specialist services may increase as publicity surrounding the service increases, and may differ in rural and urban communities.

\section{Nicotine replacement therapy}

Nicotine replacement therapy now comes in six different forms: chewing gum (2 $\mathrm{mg}$ and $4 \mathrm{mg}$ ), transdermal patch (16 hour and 24 hour in varying doses), nasal spray, inhalator, sublingual tablet, and lozenge. ${ }^{40}$

EFFICACY

1 Nicotine replacement therapy is effective in aiding smoking cessation. It reduces the urges to smoke and other withdrawal symptoms following cessation. ${ }^{41}$ Table 1 shows the incremental abstinence rates (over and above any placebo effects) at six months or longer.

2 There appears to be little difference overall in the effectiveness of different types of NRT on cessation. One study which directly compared four of the six products found no difference in abstinence rates or withdrawal discomfort. ${ }^{42}$ Although the effect sizes in the meta-analyses for the products are slightly different, these differences are not statistically significant (table 1).

$34 \mathrm{mg}$ nicotine gum may be more effective than $2 \mathrm{mg}$ gum in helping heavy smokers to stop. Research has found that highly dependent smokers benefited more from $4 \mathrm{mg}$ than $2 \mathrm{mg}$ gum. ${ }^{41}$ The definition of "highly dependent" in the three studies concerned was based on questionnaire measures relating to amount and pattern of smoking or feelings of dependence, but for operational purposes can be approximated by 20 or more cigarettes per day.

4 The standard strength patches are more effective than their lower dose counterparts in medium to heavy smokers. Research comparing the $21 \mathrm{mg}$ (standard dose) 24 hour patch with lower dose patches in smokers of more than 10 cigarettes per day found the standard dose patch to be more effective. ${ }^{43}$

5 Support from health professionals is probably not essential for NRT to be effective although it is important in its own right (see above). Placebo controlled trials of NRT in a simulated over the counter (OTC) setting have yielded similar effect sizes to studies involving more intensive behavioural support. ${ }^{44}$ However, to date studies of this type have typically involved a substantial amount of contact and monitoring which would not occur in true OTC settings. A field study (not a randomised controlled trial) in the US found similar success rates when NRT was prescribed by physicians as when purchased OTC. ${ }^{46}$

6 Combining the patch with other forms of NRT may be more effective than the patch alone and appears to be safe. Current restrictions on the use of more than one form of NRT are not supported by the scientific evidence. Although relatively little research has been conducted on NRT combinations, the research that exists suggests that combining different forms is both safe and effective. ${ }^{47}$

7 Strong evidence that NRT is effective is limited to adult smokers of 10 or more cigarettes per day not suffering from manifest smoking related diseases. There is currently insufficient research on the use of NRT in light smokers, smokers under the age of 18, pregnant smokers, and inpatient smokers. Evidence on the effectiveness of NRT among smokers with manifest smoking related diseases is mixed. ${ }^{48-50}$

8 NRT appears to be safe when given to smokers with cardiovascular disease. Evidence from studies where NRT has been given to patients with cardiovascular disease have not revealed significant adverse effects. ${ }^{51}$

9 It is unclear how far NRT would carry a risk to the fetus when used in pregnancy but it is almost certainly safer than smoking. Small studies on the effects of NRT on the fetus have not revealed significant problems. ${ }^{52}{ }^{53}$ Evidence 
from smokeless tobacco users in India suggest that nicotine may be to some extent implicated in low birth weight. ${ }^{54}$ However, NRT does not contain the large number of other toxins contained in tobacco smoke and therefore would be expected to be considerably safer than smoking.

10 There is currently little scientific basis for matching particular smokers to particular forms of NRT. ${ }^{40}$ Many flow charts and decision aids have been developed to help health professionals and smokers to choose between NRT products (gum, patch, inhalator, etc) but these are based on common sense only.

IMPLEMENTATION ISSUES

1 Approximately $25 \%$ of quit attempts involve the use of NRT with the transdermal patch being the most popular formulation with smokers. (The majority of smokers attempt to quit using willpower alone, which is the least effective method.) In a number of settings (including OTC sales, smokers' clinics, and hospital inpatients) the nicotine patches were preferred by smokers given the choice..$^{55-57}$

2 Most GPs report believing that NRT is effective and recommending patients to use it. A recent survey of GPs found that most report accepting the effectiveness of NRT and recommending it or prescribing it, usually on a private prescription. ${ }^{58}$

\section{Bupropion (Zyban)}

Bupropion has been licensed for the treatment of tobacco dependence. While originally developed as an antidepressant in the US, its efficacy in smoking cessation appears to be independent of its antidepressant effect. Bupropion comes in sustained release tablets. The standard dose is $300 \mathrm{mg}$ per day.

\section{EFFICACY}

1 Bupropion is an effective aid to smoking cessation. There is evidence from a meta-analysis of the two published trials of this drug that it improves 12 month sustained abstinence rates and reduces the severity of withdrawal symptoms (table 1)..$^{59} 60$

2 There is a very small but non-zero risk of serious adverse effects. The risk of seizures is broadly similar to other antidepressants at one in $1000 .{ }^{61}$ The risk of an allergic reaction is one in 10000 to one in $1000 .^{61}$

3 Evidence on the effectiveness of bupropion is limited to medium to heavy smokers receiving behavioural support. Published trials have included smokers of 15 or more cigarettes per day attending frequent behavioural counselling sessions.

4 It is not yet clear whether bupropion is more effective than NRT. One randomised placebo controlled trial has found a higher one year sustained abstinence rate with bupropion than a transdermal patch in the context of a behavioural support package ${ }^{60}$ Further research is needed before any firm conclusions can be drawn.

\section{IMPLEMENTATION ISSUES}

1 Putting bupropion and NRT on NHS prescription may lead to problems for specialist smokers' clinics if they are unable to prescribe bupropion. If specialist clinics are unable to offer NHS prescriptions for bupropion, this may drive smokers away from these clinics.

2 There are currently no published trials of bupropion with minimal behavioural support. Studies have so far included support; research is needed into the use of bupropion with limited input from a GP.

\section{Self-help materials}

EFFICACY

1 Written self-help materials can be effective in aiding cessation attempts. Approximately one in 100 smokers using generic self-help materials and receiving no other form of assistance stop for at least six months who would not otherwise have done so. ${ }^{62}$ It is unclear how far adding self-help materials to other forms of intervention such as brief advice to stop is effective. ${ }^{62}$

2 Materials that are tailored to the characteristics of a particular smoker can be more effective than generic materials. There is limited research comparing generic and tailored materials and in those studies varying approaches to tailoring have been adopted. However, such research as there is suggests that tailoring in some form may be helpful. ${ }^{62}$

\section{IMPLEMENTATION ISSUES}

1 Strong claims for effectiveness are made for some self-help materials such as books which are not supported by controlled trials. Self-help books can be very popular but are typically not subjected to appropriate tests of effectiveness and so claims of high success rates should be viewed with caution.

\section{Telephone counselling}

Telephone counselling comes in two main forms: "reactive counselling" where smokers call a help line seeking help and advice and "proactive counselling" where smokers receive calls from counsellors according to a prearranged schedule.

EFFICACY

1 Proactive, frequent telephone counselling can be effective as an aid to smoking cessation. There is limited evidence from controlled trials but such evidence as exists suggests an effect. ${ }^{63} 64$

2 Reactive telephone counselling may be effective as an aid to smoking cessation but is difficult to evaluate in randomised trials. There are no adequate randomised controlled trials published to date, ${ }^{63}$ but a follow up study of the then English QUITLINE (a reactive telephone counselling service) 
found high self-reported sustained abstinence rates. ${ }^{65}$ Without control groups it is not possible to assess whether these are higher than would have been the case without counselling.

\section{IMPLEMENTATION ISSUES}

1 Telephone help lines can be a popular choice for smokers who want help with stopping smoking. The use of the then English QUITLINE was very high and it was highly responsive to promotional campaigns. ${ }^{65}$ Research into the efficacy of reactive helplines is urgently needed.

\section{Examples of intervention effects at a} national level

This section gives some examples of the likely effectiveness of the key NHS interventions if implemented at a national level in England. It focuses on interventions for which there is clear evidence of effectiveness that can be delivered by the NHS. Of 40 million adults aged 16 or over in England, approximately 11 million are cigarette smokers. The background cessation rate in the population (which may include attempts prompted by GP advice) is currently estimated at $2 \%$ each year, which represents approximately 220000 smokers. $^{9}$ The NHS contribution to this may be around 32000 (assuming an estimated $29 \%$ of smokers receive advice from their GP to stop in a given year $^{4}$ and a $1 \%$ cessation rate in response to that advice).

If every GP in England were to advise 50\% of their smoking patients to stop once in a given year, that alone would lead at least $\mathbf{5 5 0 0 0}$ smokers to stop smoking long term ( $1 \%$ of 5.5 million smokers, using the most conservative figure for efficacy). This would take approximately 460000 hours of GP time (assuming five minutes per advice session). Approximately eight hours of GP time would be required per ex-smoker created (assuming the lower effectiveness figure of $1 \%$ ), and each GP would spend approximately 20 hours over the course of the year on this task.

If, when advising smokers to stop, GPs were to succeed in getting $50 \%$ of those who make an attempt to quit to use NRT instead of the current figure of approximately $25 \%$, an estimated additional 27000 smokers would stop smoking long term (assuming a 5\% effect of NRT on $25 \%$ of the $40 \%$ of smokers who make an attempt to quit in response to GP advice).

If, when advising smokers to stop, GPs were to get $5 \%$ of those who make an attempt to quit to attend a specialist clinic that used NRT or bupropion, an estimated additional 16000 would stop smoking long term (assuming a 15\% effect of the behavioural treatment plus medication on $5 \%$ of the $40 \%$ of smokers who attempt to stop in response to GP advice).

If, in addition, smoking cessation clinics engaged in promotional activities that recruited an additional $0.5 \%$ of smokers who want to stop but have not been advised to by their GP, an estimated additional 2900 would stop smoking long term (assuming a $15 \%$ effect of behavioural treatment plus medication on $0.5 \%$ of $70 \%$ of 5.5 million smokers not advised to stop by their GP).

In total, a comprehensive package of opportunistic advice, referral, and publicity for specialist clinics could result in an additional 100900 smokers stopping long term annually. The additional effects at a national level of telephone counselling and provision of selfhelp materials for smokers not using other services are more difficult to quantify.

\section{Recommendations}

For this update the recommendations are made in terms of key organisations within the health service-primary health care teams, hospitals and community trusts, and health purchasers (which may include primary care trusts) - and are summarised in the box on page 988 .

PRIMARY HEALTH CARE TEAMS

1 Primary health care teams should ensure that their records concerning which of their patients smoke are kept up to date.

Strength of evidence: A

Smoking status may well change after initial registration. Unless GPs know which of their patients smoke, they will not be in a position to provide advice on cessation. Updating records can be achieved by ensuring that patients are asked about their smoking on a fairly regular basis when they visit the surgery (at least once a year) and keeping a note of when the question was last asked. ${ }^{6}$

2 GPs should advise current smokers to stop during routine consultations at least once a year, offer a prescription for NRT or bupropion, offer further support by way of referral to a specialist clinic or other specialist service, record the response to that advice, and arrange follow up where appropriate.

Strength of evidence: A

The advice should not be limited to patients with smoking related diseases but it may help to link advice to patients' reasons for consulting because some patients are sometimes resistant to receiving advice that is not so linked. ${ }^{21}$ Also, advice that is made relevant to individual patients is likely to be better received than less specific advice. ${ }^{21}$ Once the advice has been given, it should be recorded in the patient's notes and the patient's response noted. It is vital that, when a smoker indicates that he or she is ready to stop, help is offered to facilitate the quit attempt. This will typically take the form of referral to a specialist service and advice on use of appropriate medication (see below). The following categories of patient response may apply:

(1) Not intending to stop. No interest in stopping and no negative thoughts about smoking.

(2) Not intending to stop but displaying some ambivalence or concern about their smoking.

(3) Would like to try to stop without further assistance: a quit date should be set, 
written support materials and a national telephone help line number given out, and advice given on NRT and/or bupropion with a prescription where appropriate.

(4) Would like to stop and would like assistance: refer to a specialist clinic or, if that is not appropriate, refer to other specialist service such as a trained practice nurse or pharmacist.

3 Practice nurses should be prepared to encourage known smokers to stop and offer assistance where possible.

Strength of evidence: $\mathbf{C}$

Although there is little evidence currently to support this activity, unless they are specifically employed to do this, encouraging and supporting lifestyle changes is part of the role of the practice nurse and smoking is an important element of this. Practice nurses may also be an important avenue for the provision of further prescriptions of NRT and bupropion for smokers who are conforming to a quit plan. If 4-6 weeks' free supply of NRT (provided for by the White Paper initiative) is still current policy, then practice nurses may be providing the free NRT for smokers who are eligible to receive it (smokers in England who are entitled to free prescriptions, which includes those on income support, are currently entitled through the new smoking cessation services to receive vouchers for 4-6 weeks' supply of free NRT from an accredited smoking cessation provider which may include practice nurses). As far as possible, the advice should follow the principles adopted in specialist smokers' clinics. These include:

(1) Setting a definite quit date within 1-2 weeks of the first consultation.

(2) Emphasising complete abstinence as the goal.

(3) Assessing the suitability of the client for bupropion or NRT and strongly recommending one or other unless contraindicated.

(4) If NRT is to be used, facilitating the process of obtaining a prescription, providing clear and accurate advice on use of NRT including side effects that may be experienced and what it can and cannot achieve.

(5) If bupropion is to be used, facilitating the process of obtaining a prescription, providing clear and accurate advice on the use of bupropion including side effects that may be experienced and what it can and cannot achieve, and integrating this into the counselling support.

(6) Encouraging smokers to find a partner with whom they can make the quit attempt, and maintain close contact with that partner.

(7) Checking abstinence by measurement of carbon monoxide in expired air.

(8) Arranging follow up sessions on a weekly basis for at least four weeks.

4 GPs and practice nurses should receive sufficient practical and theoretical training to enable them to deliver opportunistic advice to encourage and support a cessation attempt, and to offer accurate advice on NRT or bupropion.
Strength of evidence: A

GPs and practice nurses need to be able to appreciate the value of brief advice, have the practical skills necessary to give it effectively, and be knowledgeable about NRT and bupropion to avoid giving misleading advice to patients.

5 Other primary health care team professionals should be encouraged to ask about smoking and advise smokers to stop.

Strength of evidence: $\mathbf{C}$

Although the evidence is currently lacking for most professional groups, because of their access to smokers we recommend that other professional groups routinely ask about smoking, advise smokers to stop, and recommend sources of support where appropriate.

HOSPITALS AND COMMUNITY TRUSTS

6 Hospitals and midwifery services should implement efficient systems for recording the smoking status of outpatients and inpatients and keeping these records up to date.

Strength of evidence: A

Accurate up-to-date information on smoking status should be prominently displayed in relevant patient notes or computer records so that it is readily accessible at any time. This is a prerequisite for the provision of opportunistic advice as well as support for smokers who want it.

7 Hospitals should be smoke-free and all patients should be advised of this at the earliest opportunity-for example, for elective admissions it should be stated in correspondence before the patient arrives.

Strength of evidence: $\mathbf{C}$

There should be prominent notices notifying staff and patients of the policy and the policy should be strictly enforced. In the USA hospitals are smoke-free. The policy is strictly enforced and there are no areas for people to smoke. This policy has proved effective and workable and is a condition of the hospital's accreditation. Implementing this recommendation will probably require a directive from the Department of Health. A possible exception to this is terminally ill patients who have smoked all their lives.

8 Where practicable, current smokers attending hospital should receive opportunistic advice from a clinician similar to that described above for GPs and the advice should be recorded in the notes.

Strength of evidence: A

The frequency and nature of the advice will vary with the situation. It may be one-off advice for patients before attending for elective surgery or more regular advice for patients attending outpatient clinics on a long term basis. Each hospital department will need to determine a policy reflecting its own needs and opportunities.

9 Hospital inpatient and outpatient smokers should be offered specialist support and hospital outpatients should be 
offered NRT or bupropion on NHS prescription.

Strength of evidence: A

For inpatients this may involve limited counselling at the bedside or more intensive support extending beyond the period of treatment, depending on the circumstances. The support should be provided by a smoking cessation specialist employed for the purpose. We therefore recommend that each hospital should have a smoking cessation specialist. Practical considerations will typically dictate that the offer be made by routine provision of leaflets prior to or on attendance at the hospital supplemented by a verbal offer by health care staff, rather than having a counsellor proactively seeking out smokers

10 Pregnant smokers should receive clear, accurate, and specific information on the risks of smoking to the fetus and themselves and be advised to stop smoking.

Strength of evidence: A

This may best be delivered by the GP when the smoker first presents but should, in any event, be reinforced by the midwife during the booking visit. Although there is no evidence base to support midwife delivered advice, it is a basic right of pregnant smokers to be advised of the specific risks.

11 Pregnant smokers should be offered specialist support with stopping smoking.

Strength of evidence: A

Although only a minority of mothers may take up this support, the evidence indicates that it can be effective. In general it should be made as convenient as possible for the mother to receive this support.

12 Clinicians, midwives, and other staff who may be involved in discussing smoking with patients or clients should receive adequate training to enable them to do this effectively.

Strength of evidence: $\mathbf{C}$

This should involve theoretical and practical training on how to give advice, on facts about smoking, on methods of stopping such as NRT and bupropion, and services on offer.

SPECIALIST SMOKING CESSATION SERVICES

13 Where possible, smokers should have access to a specialist smokers' clinic.

Strength of evidence: A

In areas with good public transport and a high population density the clinic may be centrally located. In other areas it may be necessary to employ a peripatetic cessation specialist who can see clients in local health centres or provide specialist training to health centre staff.

14 Specialist clinics and other support services should be staffed by individuals specially trained and employed for the purpose rather than attempting to fit the job in with other duties.

Strength of evidence: A

Providing effective support and accurate advice and information requires someone (irrespective of professional discipline) who is trained, using the skills on a regular basis, who and keeps up or is kept up with the research.

15 The extent of provision of specialist smokers' clinics should be commensurate with demand.

Strength of evidence: $\mathbf{C}$

Overprovision of services will result in low morale among staff and wasted resources. Current evidence suggests a demand for one full time clinic or its equivalent per average sized health authority. However, this may change if smoking cessation services are more heavily promoted.

16 Clinics should offer both individual and group treatment.

Strength of evidence: A

Where groups are used, there is some evidence to suggest that they should be "group orientated" rather than "therapist orientated", aiming to foster group cohesion. ${ }^{66}$ In general group sizes should be as large as possible, up to about 30 clients. There is a danger that, when people start dropping out of small groups, the remaining clients feel isolated and suffer a drop in morale.

Protocols should also be developed for individual treatment. Group treatment is sometimes not possible and some smokers will prefer to be seen individually.

17 Specialist services should incorporate advice to use NRT or bupropion into the regimen.

Strength of evidence: A

Advice on appropriate use of and expectations surrounding NRT and bupropion is a key part of the package offered by the withdrawal orientated treatment model. ${ }^{67}$

18 The withdrawal orientated treatment model offers a practicable and proven system for most specialist services.

Strength of evidence: $\mathbf{C}$

There is insufficient evidence from controlled trials that would enable detailed guidance to be given about what elements of a behavioural support package to include or exclude. However, the withdrawal orientated model as a package is known to produce cessation rates as good as any encountered elsewhere and is well documented. ${ }^{67}$

HEALTH CARE PURCHASERS

19 Purchasing smoking cessation interventions represents an extremely cost effective way of reducing ill health and prolonging life.

Strength of evidence: A

The case for spending money on encouraging and assisting cessation is very clear with interventions typically costing under $£ 1000$ per life year saved. ${ }^{3}$ This is true for opportunistic brief interventions with unselected smokers, for NRT, bupropion, and for specialist clinics. All of these elements represent extremely good value for money.

20 The precise blend of intervention elements (opportunistic advice, specialist support from trained staff, specialist clinics, free NRT, etc) will depend on 
the local circumstances, but it should place greatest emphasis on elements that have the strongest evidence base. Strength of evidence: A

These include brief opportunistic advice from GPs, provision of NRT or bupropion, and specialist support from trained staff employed for the purpose. Pharmacists who are willing to offer a structured smoking cessation intervention to their clients may provide a useful element of the overall provision. Attempting to set up multiple clinics serving small populations is not recommended, although in rural communities it may be necessary for the specialist to travel to a location near to the clients to deliver the service rather than vice versa. Telephone support lines should also be given strong consideration; this would normally involve advising smokers to contact a national telephone help line but, in special cases, there may be a case for setting up special lines for particular purposes. Publicising and profiling all the services will be important; other promising models should be evaluated.

21 Consideration should be given to establishing a core syllabus and national accreditation for training for opportunistic interventions and for those delivering the specialist services to ensure a minimum standard.

Strength of evidence: $\mathbf{C}$

At present there are no checks on the quality of the training provided or the accuracy of the information being conveyed, yet purchasers of training are not in a position to know what constitutes high quality training.

22 Training for those not paid to do smoking cessation as a main part of their work should be purchased to enable cessation interventions to be implemented effectively; this should not detract from funding for a core specialist service.

Strength of evidence: A

Training for midwives, dentists, and other health professionals is important but the evidence base for the effectiveness of their role is currently limited.

PHARMACOTHERAPIES (NRT AND BUPROPION)

23 Smokers of 10 or more cigarettes per day should normally be encouraged to use NRT or bupropion.

Strength of evidence: A

The evidence continues to show that it increases the chances of success and reduces withdrawal discomfort.

24 There is currently no scientific basis for recommending one form of NRT over others.

Strength of evidence: $\mathbf{B}$

There is no scientific case for attempting to match individual smokers to particular forms of NRT. However, heavy smokers (more than 20 per day) should use $4 \mathrm{mg}$ rather than $2 \mathrm{mg}$ chewing gum and smokers of more than 10 per day should use the standard dose of transdermal patch rather than low dose versions (either $21 \mathrm{mg} 24$ hour patch or $15 \mathrm{mg} 16$ hour patch).
The form of NRT is probably best determined by the smoker's personal preference and tolerance for side effects.

25 There is no scientific basis for disallowing different forms of NRT to be combined and there may be some benefit to combinations.

Strength of evidence: B

Combining different forms of NRT such as patch and nasal spray has not been found to be harmful in clinical trials and may improve success rates.

26 NRT can be recommended for use in patients with cardiovascular disease, but only with the agreement of the patient's physician if the disease is acute or poorly controlled.

Strength of evidence: $\mathbf{B}$

There is no scientific basis for disallowing the use of NRT in patients with cardiovascular disease. More detailed guidelines on the use of NRT in these patients are given elsewhere. ${ }^{6}{ }^{68}$ There is no evidence that NRT is harmful in patients with cardiovascular disease and the benefits from stopping smoking are considerable. At the same time, evidence is conflicting on whether patients with manifest cardiovascular disease are helped by NRT.

27 Use of NRT by pregnant smokers may benefit the mother and fetus if it leads to cessation of smoking.

Strength of evidence: $\mathbf{C}$

There is some evidence that nicotine may be implicated in some of the damage to the fetus from smoking in pregnancy, but the harm from NRT would be expected to be less than from smoking. Therefore a judgement needs to be made in each case about whether the mother would be able to stop without NRT. If NRT is used it would be prudent to advise more strongly than usual that it be stopped if the mother resumes smoking. In addition, it may be preferable for patients to use oral dosing forms rather than transdermal patches because nicotine levels can be reduced more rapidly in the event of problems.

28 NRT may aid smoking cessation in adolescent smokers but there is insufficient evidence yet to make a recommendation.

Strength of evidence: C

One might argue that there is no reason to believe that NRT would be any less effective in adolescents than in adult smokers but, on the other hand, the lability of motivation to stop in adolescents may limit the effectiveness of NRT. 29 No recommendation can currently be made concerning the circumstances in which bupropion should be preferred over NRT or vice versa other than those for which one of the drugs is contraindicated.

Strength of evidence: B

It is imperative, however, that smokers be given accurate and balanced information on the effectiveness and safety of these drugs.

30 No recommendation can be made regarding the use of NRT and bupropion in combination.

Strength of evidence: $\mathbf{B}$ 
Although one study found that the combination was better than nicotine patch alone,${ }^{60}$ this finding needs to be replicated before a firm recommendation can be made.

\section{Both NRT and bupropion should be} available on NHS prescription.

Strength of evidence: $\mathbf{A}$

They are both effective and cost effective life preserving treatments and making one available on the NHS and the other not available on the NHS is unreasonable and likely to cause problems in the delivery of services where only NRT or only bupropion is available. ${ }^{4}$

32 Both bupropion and NRT should be prescribed for relatively short durations at a time and the prescriptions only repeated if the quit attempt is continuing.

Strength of evidence: A

There is good evidence that a high proportion of smokers making an attempt to quit will either fail to quit at all or relapse within the first few weeks. ${ }^{69}$ To supply the full course is therefore wasteful. It makes sense to provide pharmacotherapies only for as long as the quit attempt is continuing. ${ }^{70}$ There is limited evidence that subjects continue to make quit attempts for several weeks after the end of treatment with bupropion. ${ }^{60}$ Bearing this in mind, it makes sense to prescribe bupropion for four weeks and to provide a further month's treatment if the quit attempt is continuing or the smoker is conforming to an agreed smoking cessation programme. ${ }^{70}$

\section{Conclusions}

The key recommendations of the 1998 guidelines are reinforced and the update has provided an opportunity to provide additional clarity and detail. Brief opportunistic advice from GPs remains an important element as do NRT and provision of behavioural support. Key new features of the update are:

- Clarification on what it would be reasonable and useful to expect primary health care teams to undertake.

- The recommendation that smokers be referred to specialist smokers' clinics as the first line of referral for smokers wanting help beyond what can be provided through brief advice from the GP.

- A key distinction between behavioural support provided by trained smoking cessation specialists (for which there is good evidence of effectiveness) and more limited support provided by other health care professionals as part of their routine duties (for which there is limited evidence of effectiveness).

- The recommendation that both bupropion and NRT should be available on reimbursable NHS prescriptions.

- Recommendations concerning bupropion.

- Provision of more information on the scope of evidence relating to NRT.

- The recommendation that hospitals should be smoke-free and that this policy should be strictly enforced.

As new evidence emerges, particularly on implementation of smoking cessation services, the guidelines will need further updating.
There are approximately 170 papers published each month on smoking and, in addition, new guidance may be required as experience in delivery of the NHS service accumulates.

This work was funded by the Health Education Authority and the Health Development Agency.

\section{Appendix A: List of reviewers}

Professor John Britton, Professor of Respiratory Medicine, Department of Medicine, University of Nottingham, City Hospital, Nottingham, UK

Dr Tim Coleman, Senior Lecturer, Department of General Practice and Primary Health Care, University of Leicester, Leicester General Hospital, UK

Dr Jonathan Foulds, Director of the Tobacco Dependence Program, University of Medicine and Dentistry, New fersey, USA

Professor Godfrey Fowler, Emeritus Professor of General Practice, University of Oxford, UK

Professor Christine Godfrey, Professor of Health Economics, Centre for Health Economics, University of York, York, UK

Professor Peter Hajek, Professor of Clinical Psychology, St Bartholomew's and the Royal London School of Medicine and Dentistry, University of London, UK

Professor Martin Jarvis, Assistant Director, Health Behaviour Unit, Department of Epidemiology and Public Health, University College London Medical School, London, UK

Dr Tim Lancaster, Co-ordinating Editor, Cochrane Tobacco Addiction Review Group, ICRF General Practice Research Group, University of Oxford, Division of Public Health and Primary Health Care, Institute of Health Sciences, Oxford, UK

Dr Dawn Milner, Senior Medical Officer, Department of Health, London, UK

Dr Lesley Owen, Senior Research Manager, Health Development Agency, London, UK

Professor Michael Russell, Emeritus Professor of Addictions, National Addiction Centre, Institute of Psychiatry, University of London, London, UK

Dr John Stapleton, Senior Lecturer, King's College London, Institute of Psychiatry, University of London, UK

Dr Lindsay Stead, Cochrane Tobacco Addiction Review Group, ICRF General Practice Research Group, University of Oxford, Division of Public Health and Primary Health Care, Institute of Health Sciences, Oxford, UK

Dr Gay Sutherland, Honorary Consultant Clinical Psychologist, King's College London, Institute of Psychiatry, University of London, UK

\section{Appendix B: List of endorsers}

ASH, ASH Scotland, British Dental Association, The British Dental Hygienists' Association, British Heart Foundation, British Lung Foundation, British Thoracic Society, Cancer Research Campaign, Chartered Society of Physiotherapy, Community Practitioners' \& Health Visitors' Association, Faculty of General Dental Practitioners, Imperial Cancer Research Fund, National Asthma Campaign, National Heart Forum, National Pharmaceutical Association, National Primary Care Facilitation Programme, No Smoking Day, Pharmacy Healthcare Scheme, QUIT, Royal College of General Practitioners, Royal College of Midwives, Royal College of Nursing, Royal College of Physicians, Royal Pharmaceutical Society of Great Britain, The Royal College of Surgeons.

1 Raw $\mathrm{M}, \mathrm{McNeill} \mathrm{A}$, West R. Smoking cessation guidelines for health professionals. A guide to effective smoking cessation interventions for the health care system. Thorax 1998;53(Suppl 5, Pt 1):S1-19.

2 Department of Health. Smoking kills: a White Paper on tobacco. London: The Stationery Office, 1999.

3 Parrott S, Godfrey C, Raw M, et al. Guidance for commisParrott S, Godfrey C, Raw M, et al. Guidance for commis-
sioners on the cost effectiveness of smoking cessation intersioners on the cost effectiveness of smoking cessa
ventions. Thorax 1998;53(Suppl 5, Pt 2):S1-38.

4 McNeill A, Bates C. Smoking cessation in primary care. London: ASH, 2000. 
5 Department of Health. National service framework for coronary heart disease. London: The Stationery Office,

6 USDHHS. Treating tobacco use and dependence. Rockville, MD: Agency for Healthcare Research Quality, 2000.

7 Society for Research in Nicotine and Tobacco (SRNT) SRNT treatment database treatobacco.net. Washington: Society for Research in Nicotine and Tobacco, 2000

8 Bates C, McNeill A, Owen L. Smoking cessation services: implementing the NHS national plan. London: ASH, 2000.

9 Royal College of Physicians. Nicotine addiction in Britain. London: Royal College of Physicians, 2000.

10 The NHS plan. A plan for investment, a plan for reform. Presented to Parliament by the Secretary of State for Health by command of Her Majesty. July 2000. CM 4818-I.

11 Fiore M, Bailey W, Cohen S, et al. Smoking cessation clinical practice guideline no. 18. Rockville: Agency for Health Care Policy and Research, US Department of Health and Human Services, 1996.

12 Silagy C. Physician advice for smoking cessation. Cochrane Database Syst Rev 2000;2:CD000165.

13 Russell MA, Wilson C, Taylor C, et al. Effect of general

practitioners' advice against smoking. BMF 1979;2:231-5.
4 Kreuter MW, Chheda SG, Bull FC. How does physician advice influence patient behavior? Evidence for a priming effect. Arch Fam Med 2000;9:426-33.

15 Richman PB, Dinowitz S, Nashed AH, et al. The emergency department as a potential site for smoking cessation intervention: a randomized, controlled trial. Acad Emerg Med 2000;7:348-53.

16 Senore C, Battista RN, Shapiro SH, et al. Predictors of smoking cessation following physicians' counseling. Prev Med 1998;27:412-21.

17 West R, McEwen A, Bolling K, et al. Smoking cessation and smoking patterns in the general population: a one-year follow-up. Addiction 2000 (in press).

18 McEwen A, West R. Smoking cessation activities by GPs and practice nurses. Tobacco Control 2000 (in press).

19 Coleman T, Murphy E, Cheater F. Factors influencing discussion of smoking between general practitioners and cussion of smoking between general practitioners and
patients who smoke: a qualitative study. $\mathrm{Br} \mathcal{7}$ Gen Pract patients who smok

20 Coleman T, Wilson A. Factors associated with the provision of anti-smoking advice by general practitioners. $\mathrm{Br} \mathcal{F} \mathrm{Gen}$ Pract 1999;49:557-8.

21 Butler CC, Pill R, Stott NC. Qualitative study of patients' perceptions of doctors' advice to quit smoking: implications for opportunistic health promotion. BMf 1998;316 1878-81.

22 Stott NC, Pill RM. Health promotion and the human response to loss: clinical implications of a decade of primary health care research. Fam Pract 1987;4:278-86.

23 Lancaster T, Stead LF. Individual behavioural counselling for smoking cessation. Cochrane Database Syst Rev 2000;2: CD001292.

24 Anthonisen NR, Connett JE, Kiley JP, et al. Effects of smoking intervention and the use of an inhaled anticholinergic ing intervention and the use of an inhaled anticholinergic
bronchodilator on the rate of decline of FEV bronchodilator on the rate of decline of

25 Rice VH, Stead LF. Nursing interventios for smoking cessation. Cochrane Database Syst Rev 2000;2:CD001188.

26 Steptoe A, Doherty S, Rink E, et al. Behavioural counselling in general practice for the promotion of healthy behaviour among adults at increased risk of coronary heart disease: randomised trial. BMF 1999;319:943-7; discussion 947-8.

27 Sinclair HK, Bond CM, Lennox AS, et al. Training pharmacists and pharmacy assistants in the stage-of-change model of smoking cessation: a randomised controlled trial in Scotland. Tobacco Control 1998;7:253-61.

28 McGuire TA, McElnay JC, Drummond A. A randomised controlled trial of a smoking cessation intervention based in community pharmacies. Addiction 2000 (in press).

29 Stead LF, Lancaster T. Group behaviour therapy programmes for smoking cessation. Cochrane Database Syst Rev 2000;2:CD001007

30 Moolchan ET, Ernst M, Henningfield JE. A review of tobacco smoking in adolescents: treatment implications. $\mathscr{F}$ Am Acad Child Adolesc Psychiatry 2000;39:682-93.

31 Lumley J, Oliver S, Waters E. Interventions for promoting smoking cessation during pregnancy. Cochrane Databas Syst Rev 2000;2:CD001055.

32 Melvin CL, Dolan-Mullen P, Windsor RA, et al. Recommended cessation counselling for pregnant women who smoke: a review of the evidence. Tobacco Control 2000 9(Suppl 3):III80-4.

33 West R. Smoking cessation interventions in pregnancy: guidance to purchasers and providers. London: HEA, 1994

34 Wisborg K, Henriksen TB, Secher NJ. A prospective intervention study of stopping smoking in pregnancy in a routine antenatal care setting. $\mathrm{Br} / \mathrm{f}$ Obstet Gynaecol 1998;105:1171-6.

35 Hajek P, West R, Lee A, et al. Randomised controlled trial of a midwife-delivered brief smoking cessation intervention in pregnancy. Addiction 2000 (in press).

36 May S, West R. Do social support interventions ('buddy systems') aid smoking cessation? A review. Tobacco Control 2000 (in press).

37 Ussher MH, Taylor AH, West R, et al. Does exercise aid smoking cessation? A systematic review. Addiction 2000;95: 199-208.
38 West R. Getting serious about smoking cessation: a review of products, services and techniques. London: No Smoking Day, 999.

39 Turner RG, Pagoin JC, Martinez V, et al. Promoting smoking cessation in general practice. BMF 1993;307:939.

40 Nicotine replacement to aid smoking cessation. Drug Ther Bull 1999;37:52-4.

41 Silagy C, Mant D, Fowler G, et al. Nicotine replacement therapy for smoking cessation. Cochrane Database Syst Rev 2000;2:CD000146.

42 Hajek P, West R, Foulds J, et al. Randomised comparative rial of nicotine polacrilex, a transdermal patch, nasal spray and an inhaler. Arch Intern Med 1999;159:2033-8.

43 Daughton DM, Fortmann SP, Glover ED, et al. The smoking cessation efficacy of varying doses of nicotine patch delivery systems 4 to 5 years post-quit day. Prev Med 1999; 28:113-8.

44 Hays JT, Croghan IT, Schroeder DR, et al. Over-the-counter nicotine patch therapy for smoking cessation: results from randomized, double-blind, placebo-controlled, and open label trials. Am $\mathcal{7}$ Public Health 1999;89:1701-7.

45 Davidson M, Epstein M, Burt R, et al. Efficacy and safety of an over-the-counter transdermal nicotine patch as an aid for smoking cessation. Arch Fam Med 1998,7.569-74.

46 Shiffman S, Gitchell J, Pinney JM, et al. Public health benefit of over-the-counter nicotine medications. Tobacco Control 1997;6:306-10.

47 Stapleton J. Commentary: Progress on nicotine replacement therapy for. $B M \mathcal{F} 1999 ; \mathbf{3 1 8}: 289$

48 Campbell IA, Prescott RJ, Tjeder-Burton SM. Transdermal nicotine plus support in patients attending hospital with smoking-related diseases: a placebo-controlled study. Respir Med 1996;90:47-51.

49 Lewis SF, Piasecki TM, Fiore MC, et al. Transdermal nicotine replacement for hospitalized patients: a randomized clinical trial. Prev Med 1998;27:296-303.

50 BTS. Comparison of four methods of smoking withdrawal in patients with smoking related diseases. Report by a Subcommittee of the Research Committee of the British Thoracic Society. BMF (Clin Res Ed) 1983;286:595-7.

51 Benowitz NL, Gourlay SG. Cardiovascular toxicity of nicotine: implications for nicotine replacement therapy. $\mathcal{F}$ Am Coll Cardiol 1997;29:1422-31.

52 Lambers DS, Clark KE. The maternal and fetal physiologic effects of nicotine. Semin Perinatol 1996;20:115-26.

53 Lindblad A, Marsal K, Andersson KE. Effect of nicotine on human fetal blood flow. Obstet Gynecol 1988;72(3 Pt 1):371-82.

54 Krishnamurthy S, Joshi S. Gender differences and low birth weight with maternal smokeless tobacco use in pregnancy. 7 Trop Pediatr 1993;39:253-4.

55 West R, Hajek P, Nilsson F, et al. Individual differences in preference for and responses to four nicotine replacement products. Psychopharmacology 2000 (in press).

56 Cummings KM, Hyland A, Ockene JK, et al. Use of the nicotine skin patch by smokers in 20 communities in the United States, 1992-1993. Tobacco Control 1997;6(Suppl 2):S63-70.

57 Shaw JP, Ferry DG, Pethica D, et al. Usage patterns of transdermal nicotine when purchased as a nonprescription medicine from pharmacies. Tobacco Control

58 McEwen A, West R. GPs' views on medications for treating tobacco dependence: a report to the HDA. London, 2000.

59 Hurt RD, Sachs DP, Glover ED, et al. A comparison of sustained-release bupropion and placebo for smoking cessation. N Engl F Med 1997;337:1 195-202.

60 Jorenby DE, Leischow SJ, Nides MA, et al. A controlled trial of sustained-release bupropion, a nicotine patch, or both for smoking cessation. N Engl F Med 1999;340:685-91.

61 GlaxoWellcome. Zyban $150 \mathrm{mg}$ tablets: summary of product characteristics, 2000

62 Lancaster T, Stead LF. Self-help interventions for smoking cessation. Cochrane Database Syst Rev 2000;2:CD001118.

63 Lichtenstein E, Glasgow RE, Lando HA, et al. Telephone counseling for smoking cessation: rationales and meta-
analytic review of evidence. Health Educ Res 1996;11:24357.

64 Zhu SH, Stretch V, Balabanis M, et al. Telephone counseling for smoking cessation: effects of single-session and multiple-session interventions. F Consult Clin Psychol 1996; 64:202-11.

65 Owen L. Impact of a telephone helpline for smokers who called during a mass media campaign. Tobacco Control 2000;9:148-54.

66 Hajek P, Belcher M, Stapleton J. Enhancing the impact of roups: an evaluation of two group formats for smokers. $\mathrm{Br}$ f Clin Psychol 1985;24:289-94.

67 Hajek P. Withdrawal-oriented therapy for smokers. $\mathrm{Br} f$ Addict 1989;84:591-8.

68 McRobbie H, Hajek P. Nicotine replacement therapy in patients with cardiovascular disease. London: Royal London Hospital, 2000.

69 Stapleton JA, Russell MA, Feyerabend C, et al. Dose effects and predictors of outcome in a randomized trial of transdermal nicotine patches in general practice. Addiction 1995;90:31-42.

70 Stapleton JA, Lowin A, Russell MA. Prescription of transdermal nicotine patches for smoking cessation in general practice: evaluation of cost-effectiveness. Lancet 1999; 354:210-5. 